\title{
A NEW LATE OLIGOCENE MYSTICETE FROM WASHINGTON STATE
}

CROWLEY*, Bruce E., Thomas Burke Memorial Washington State Museum, University of Washington, DB-10, Seattle, WA 98195, U.S.A.; BARNES, Lawrence G., Section of Vertebrate Paleontology, Natural History Museum of Los Angeles County, 900 Exposition Boulevard, Los Angeles, CA 90007, U.S.A., and Affiliate Curator, Thomas Burke Memorial Washington State Museum.

A partial skeleton of a very primitive, relatively large, baleen-bearing mysticete whale has been found in the Late Oligocene Pysht Formation on the south shore of the Straight of Juan de Fuca, Olympic Peninsula, Washington. This is the first report of such a primitive mysticete from the eastern North Pacific Ocean margin, and the fossil apparently represents a new genus and species. The specimen includes a skull with an incomplete rostrum, a complete dentary, all seven cervical vertebrae, twelve partial or complete thoracic vertebrae, eleven partial or complete lumbar vertebrae, both partial scapulae, the long bones of both forelimbs and various partial ribs. The intertemporal region of the cranium has wide exposures of the parietals, is elongate and narrow, and bears a sagittal crest. The frontals are widely exposed between the parietals and the elongate nasals. The dorsal narial opening is located relatively far anteriorly on the rostrum. These primitive cranial characters are shared with the Archaeoceti. The palate is smooth, except for nutrient grooves, indicating that baleen was present.

In traditional cetacean taxonomy this whale would probably be classified as a primitive member of the Family Cetotheriidae, and affiliated with the genus Mauicetus Benharn, 1939. The holotype of the type species of Mauicetus, M. parki (Benham, 1937) (a very incomplete braincase), has a shorter intertemporal region, so the new cetacean from Washington is more primitive than Mauicetus. The only other reported mysticete with similarly primitive characters is an undescribed taxon from the Late Oligocene Ashiya Group in Kyushu, Japan, that was reported by Okazaki (1995). These two mysticetes belong in an as-yet un-diagnosed clade of cetaceans that are intermediate between tooth-bearing mysticetes and the later, "more typical" Cetotheriidae. 